why this latter class of waves should affect the barometer more strongly in the case of the current with the eastward component. In the first place that current is proceeding from the tropics, the region in which all great atmospheric movements originate; and in the second place there is a greater mass of matter moving with it than with the other current, there being not only an equal quantity of dry air returning northwards to compensate for that which is flowing southwards, but there being also a considerable quantity of water vapour, which does not return southwards in the form of vapour, but, having been precipitated as rain, returns with the ocean currents. It may not be easy, but still it is perhaps possible, to demonstrate how this fact should explain the greater amplitude of the eastward than of the westward transmitted waves.

Meteorological Office, Bombay, September 4

\section{Apparent Disappearance of Jupiter's Satellites}

ON the morning of October 15 next Jupiter will appear to be deprived of the satellites usually attending him. This somewhat rare phenomenon has only been observed on four occasions during the present century, as follows :-

$$
\begin{array}{l|l}
\text { May 23, 1802 } & \begin{array}{l}
\text { September 27, 1843 } \\
\text { April I5, I826 }
\end{array} \\
\text { August 21, 1867 }
\end{array}
$$

In 1826 the disappearance of the Jovian moons extended over an interval of 2 hours; in 1843 the interval was thirty-five minutes; in $1867 \times$ hour 45 minutes; but on October 15 next the phenomenon only endures 19 minutes (i.e. from $3 \mathrm{~h} .56 \mathrm{~m}$. to 4h. $15 \mathrm{~m}$. a.m.). The second, third, and fourth satellites will be in transit across the disk, while the first will be occulted by the planet. On Angust 21, 1867, the first, third, and fourth were in transit, while the second was eclipsed, and afterwards occulted. These occasions offer excellent opportunities for comparing the appearance of the satellites while in transit, and for re-detecting the dusky spots which were formerly distinguished upon them by Dawes, Secchi, and others. On August 2I, 1867, I observed the phenomenon with a $4 \frac{1}{4}$ inch refractor, and noticed that the satellites appeared nearly as dark and distinct as their shadows while projected on the disk of their primary.

There is a remariable agreement in the intervals separating this rare occurrence. Between the disappearances of May 23, I802, and A pril 15,1826 , there is a period of 24 years less 38 days $(=8728$ day $)$, and between those of September $27, \mathbf{I} 843$, and August 21, 1867, 24 years less 37 days (= 8729 days). The other intervals are irregular, there being I7 years 165 days between that of I826-1843, and 16 years 55 days between that of $\mathrm{I} 867-\mathrm{I} 883$. If, how ever, there is a regularly-recurring cycle of nearly 24 years, as the above dates apparently indicate, after every alternate disappearance of these satellites, then we may expect a repetition of the phenomenon on about September 7 , I907.

Bristol, October 6, $188_{3}$

\section{The English Viper}

IN regard to the English viper, I send a small contribution to the information that Mr. R. Langdon seeks in your issue for August 2 (p. 319). During a residence of more than twenty years on the outskirts of the Forest of Dean, the following facts concerning the adder's bite came more or less under my notice :-

I. A girl was bitten on the thumb, she sucked the bite, and her head, throat, and tongue swelled so much that she nearly died of suffocation and starvation. She was laid up more or less for six months, and folks said that she was never herself again, but became "silly-like," but so far as my memory goes she was but weak minded before the bite.

2. A gamekeeper was bitten on the thick part of the hand. $\mathrm{He}$ could hardly get home, and did not leave his bed for three months afterwards.

3. A woman in the Forest was bitten on the thumb, her arm swelled, and became black, but on the application of a herb (which I cannot identify, though she called it " adder's tongue"), the swelling went down at once, and in a day or so no trace of the bite remained.

4. Though the following case did not occur in our neighbourhood, yet as the patient was a family connection, and the details were given me by his mother, I bring it forward. The young man was bi ten in the hand, and his arm swelled rapidly to such a size, that the coat sleeve had to be cut open. The youth was ill for many months, and more than a year afterwards had not regained his former mental and physical condition.

5. Cows were often bitten on the legs, but more often on the udder; they never died from the bites.

6. Sheep often died; and lambs, so far as memory serves, did so invariably.

7. A pointer was bitten on the chest. The bite did not bleed, but the dog swelled quickly and could not walk; it was ill for a long time, but did not die.

8. I remember hearing that a little girl had died from the bite of an adder; but 1 mention the case with little confidence, as it did not come within the limits of my observation.

In 1865 or 1866 adders were more numerous in our neighbourhood than the "oldest inhabitant" had ever known them to be. The farmers were advised to turn their pigs into the fields, and and the result was that wherever the pigs ranged the adders were nearly exterminated. A student of folk-lore would find a wide field in the traditions respecting the adder and its bite. In our neighbourhood the fat of the adder, especially that of the biter, was considered the best antidote for the bite. To roast an adder alive was not only a means of relieving the sufferer, but by making "the varmin squeal" it was said to draw others from their holes, and thus lead to their destruction.

\section{Katharine B. Clay pole}

Thougin not precisely in reply to Mr. Langdon's question, yet I add a short postscript to my wife's letter.

In this district we have two venomous snakes, the rattlesnake and the copperhead. The former is now becoming scarce, but the latter is still common. I have never been able to learn that any human being has been killed by the bite of either of these snakes in this neighbourhood. Bites of the rattlesnake are exceedingly rare, but I have known some, and heard of many persons who have been bitten by copperheads.

$x$. A lacly was bitten on the foot at her garden gate; the leg swelled up to the thigh, and was exceedingly painful. She was more or less ill for a week.

2. A boy was bitten on the foot, and the leg swelled and turned black. No remedies were applied for many hours. A poultice of some herb which I have not been able to identify was put on the wound, and in twelve hours more the swelling had gone down, and the boy could walk.

3. In a third case of which I have heard the wound was said to reopen, or at least to become irritable, every year at the date of the bite.

4. A friend of mine had a dog which was bitten by a copperhead. He treated the wound with new milk, but the dog died.

5. In one case of which I have heard a man was bitten by a rattlesnake, but though I do not know the details of the case, the man is still alive.

6. A dog belonging to the friend mentioned above was bitten by a rattlesnake, and treated with new milk. He recovered.

I have heard of and known other cases of snakebite, but similar results followed. The remedies recommended for snakebite are too numerous to mention. Whisky in large doses is the most popular, and it never seems in such cases to produce intoxication. The common remedy- "the fat of the snake that bit you"-is, I suspect, an ingenious device for insuring the destruction of the reptile. It would appear as if the bite of the two snakes which I have mentioned can hardly be as deadly as is commonly supposed. The frequent swelling of the head and tongue appears to me to be caused by sucking the poison from the wound when a sore may have existed in the mouth. Much probably depends on the size and condition of the snake, the time of year, and the place and depth of the bite.

New Bloomfield, Perry County, Pa., September 3

$$
\text { E. W. Claxpole }
$$

\section{Solar Halo}

I HAD the pleasure of witnessing, this morning, what $\mathrm{Mr}$. Backhouse refers to in the last number of NATURE (p. 5I5) " as seen on rare occasions - a small portion of an ordinary halo brilliantly coloured."

Looking from a window at $9.40 \mathrm{a} . \mathrm{m}$. towards the south-east, I saw a brilliant patch of light which for a moment I took to be the sun, but which I soon perceived was part of a solar halo, the sun being (roughly speaking) $20^{\circ}$ distant in a horizontal line.

The colours were exactly those of the rainbow, especially at 